\title{
Influenza B Virus
}

National Cancer Institute

\section{Source}

National Cancer Institute. Influenza B Virus. NCI Thesaurus. Code C53468.

A neg ative-strand linear single-strand RNA virus with an 8 segment genome. Virions are enveloped and usually spherical or pleomorphic, 50-120 nm in diameter. Influenza B viruses are usually found only in humans. Unlike influenza A viruses, these viruses are not classified according to subtype. 